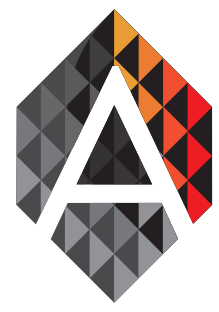

ADCAIJ: Advances in Distributed Computing and Artificial Intelligence Journal Regular Issue, Vol. 7 N. 2 (2018), 27-42

eISSN: $2255-2863$

DOI: http://dx.doi.org/10.14201/ADCAIJ2018722742

\title{
Robust and adaptive chatter free formation control of wheeled mobile robots with uncertainties
}

\author{
Maximilian Jaderson de Melo ${ }^{\mathrm{a}}$, Mauricio Begnini ${ }^{\mathrm{b}}$, Heber \\ Rabelo da Silva ${ }^{1}$, and Marcelo Christiano da França Júnior ${ }^{\mathrm{a}}$
}

${ }^{a}$ Federal Institute of Education, Science and Technology of Mato Grosso do Sul - campus Naviraí ${ }^{b}$ Federal Institute of Education, Science and Technology of Santa Catarina - campus Canoinhas maximilian. melo@ifms.edu.br,mauricio.begnini@ifsc.edu.br,hebermga@gmail.com, marcelo.franca@ifms.edu.br

$\begin{array}{ll}\text { KEYWORD } & \text { ABSTRACT } \\ \begin{array}{l}\text { wheeled mobile } \\ \text { robots; robust }\end{array} & \begin{array}{l}\text { This paper addresses the robust formation control of non-holonomic mobile robots } \\ \text { formation control; } ;\end{array} \\ \text { leader-following; } ; & \begin{array}{l}\text { it was necessary the mathematical modeling of mobile robots, from which, the Sepa- } \\ \text { stability sliding mode control. proof were based on the Lyapunov theory. The sliding } \\ \text { mode control (SMC) strategy was used in the controller design to make the control ro- } \\ \text { bust to the incidence of uncertainties and disturbances. The Fuzzy Adaptive Formation } \\ \text { Control is designed to eliminate the previous bounding knowledge of these uncertain- } \\ \text { ties and disturbances. The proposed control effectiveness is demonstrated by results } \\ \text { obtained with simulations in Matlab/Simulink. The pure kinematic and kinematic with } \\ \text { disturbances is also analyzed. The results shows the controllers effectiveness to forma- } \\ \text { tion of multi-robots systems to the eight-shaped trajectory. }\end{array}\end{array}$

\section{Introduction}

In the past few years many researches has aimed multi robot systems. There are several robotic formation approaches, in which the most common are virtual structure, behavior-based and leader-following $\mathrm{n}$ [a]. Each one of them has advantages and weaknesses. There are some other approaches, but they are less common.

In virtual structure approach, the entire formation is treated as a rigid body, and the controller is responsible to translate a control signal to each robot given a formation move. It is easy to prescribe movement to the robots in the formation and the formation holds very well during maneuvers. A weakness of this approach is that the formation is not easily modified,making it inapplicable in real scenarios.

In behavior-based approach, several desired behaviors are designed for each robot, and the final action of each robot is derived by weighting every behavior by its importance. It is a very flexible, but it is very difficult to analyze mathematically, and therefore it is difficult to guarantee the formation control stability.

In the leader-following approach, one robot is considered as a leader and the others are considered followers.

Maximilian Jaderson de Melo, Mauricio Begnini, Heber Rabelo da Silva, and Marcelo Christiano da França Júnior Robust and adaptive chatter free formation control of wheeled mobile robots with uncertainties
ADCAIJ: Advances in Distributed Computing and Artificial Intelligence Journal Regular Issue, Vol. 7 N. 2 (2018), 27-42 elSSN: 2255-2863 - http://adcaij.usal.es Ediciones Universidad de Salamanca - CC BY NC DC 
This approach has two main variants: separation bearing $(l-\Psi)$ and separation separation $(l-l)$. In $(l-\Psi)$, one robot is defined as a leader and other is the follower. To the leader is prescribed a reference trajectory and it has to solve one of three problems: point stabilization, path following and trajectory tracking. The follower needs to maintain a desired distance and relative angle. In $(l-l)$, the configuration has three robots, two leaders and one follower. The leaders are similar to $(l-\Psi)$ approach, and the follower needs to maintain desired distances to each of the leaders. This two variants may also include obstacle avoidance.

There are other approaches less popular like artificial potential field $\mathrm{w}[\mathrm{o}]$, model predictive control $\mathrm{n}[\mathrm{a}]$, flocking in fixed and switching networks e [h], feedback linearization and neural networks i [a].

In e [i], the authors employed the $(l-\Psi)$ approach including the mobile robot dynamics into the control scheme. Obstacle avoidance based on potential artificial fields was also added in the scheme. $s$ [a] has developed a control of multi-agent non-holonomic system. The control considered collision avoidance for a single robot based on potential artificial fields. The methodology was later applied in a $[\mathrm{h}]$ to in a combined formation controller. The authors have done a kinematic controller using sliding mode control. The obstacle avoidance was projected using artificial potential field with coefficient of attractive and repulsive functions determined by a fuzzy system.

In $\mathrm{n}$ [a], an adaptive neural-network control strategy integrated both kinematic controller and input voltage controller. The authors designed the control law by backstepping technique based on separation-bearing formation control structure of leader-following. Radial basis function neural network (RBFNN) was used for on-line estimation for the dynamics nonlinear uncertain part.The robust control was used to compensate the NN errors.

$\mathrm{m}$ [a] investigated the formation control and obstacle avoidance of WMR based on leader-following control approach. The obstacle avoidance is implemented based on generating a virtual force, used to apply corrections in the WMR velocities.

In this paper a robust formation control scheme based on the leader following approach and fuzzy logic is investigated. This control takes advantages of the robustness of sliding mode control (SMC) technique, and guarantee the effectiveness even when uncertainties/disturbances with unknown bounding are present in the system. In the results, simulations are presented to prove the control effectiveness.

This paper is organized as follows, section 2 describes the Wheeled Mobile Robot (WMR) kinematics. In section 3, the leader-following formation control is presented. in section 4 Variable Structure Control is presented. Section 5 presents a linear approximation based on Fuzzy logic. In section 6, simulation and numerical results are shown. Finally, section 7 brings discussion and conclusions about this paper.

\section{Mobile robot model}

Given the WMR generalized coordinates, defined as $q=\left[\begin{array}{ll}x y & y\end{array}\right]^{T}$, in which $x_{c}, y_{c}$ are the positions and $\theta_{c}$ the orientation regarding the 2-D Cartesian coordinate system. The WMR kinematic model is as follows

$$
\begin{aligned}
& \dot{q}=S(q) \eta+\delta \\
& \dot{q}=\left[\begin{array}{c}
\dot{x} \\
\dot{y} \\
\dot{\theta}
\end{array}\right]=\left[\begin{array}{cc}
\cos \theta & -d \sin \theta \\
\sin \theta & d \cos \theta \\
0 & 1
\end{array}\right]\left[\begin{array}{c}
v_{l} \\
\omega_{a}
\end{array}\right]+\left[\begin{array}{c}
\delta_{x} \\
\delta_{y} \\
\delta_{\theta}
\end{array}\right],
\end{aligned}
$$

in which $d, v_{l}, \omega_{a}$ and $\delta$ are the distance from the rear axle to the front of the WMR, the linear and angular velocities and disturbances vector, respectively. The disturbances are assumed to be upper bounded as follows

$$
\left|\delta_{x}\right| \leq \alpha_{x},\left|\delta_{y}\right| \leq \alpha_{y},\left|\delta_{\theta}\right| \leq \alpha_{\theta}
$$

in which $\alpha=\left[\begin{array}{lll}\alpha_{x} & \alpha_{y} & \alpha_{\theta}\end{array}\right]^{T}$ is the positive bounding vector.

Maximilian Jaderson de Melo, Mauricio Begnini, Heber Rabelo da Silva, and Marcelo Christiano da França Júnior Robust and adaptive chatter free formation control of wheeled mobile robots with uncertainties
ADCAIJ: Advances in Distributed Computing and Artificial Intelligence Journal Regular Issue, Vol. 7 N. 2 (2018), 27-42 eISSN: 2255-2863 - http://adcaij.usal.es Ediciones Universidad de Salamanca - CC BY NC DC 
Remark 1. The kinematic model of the WMR subject to the matched disturbances is given by

$$
\dot{q}=S(q) \eta+\rho(t)[\cos \theta \sin \theta 0]^{T},
$$

in which $\rho$ stands for the bounded disturbance.

\section{Leader-Following Formation Control}

The most popular variants of leader-following formation control are named Separation-bearing and Separationseparation $\mathrm{n}[\mathrm{a}]$; $\mathrm{e}[\mathrm{h}]$. In this paper, only Separation-bearing formation control variants are formulated, but the formulation can be easily extended to Separation-separation formation control variant. The formation formulation in this paper considers only two WMR's, one leader and one follower, identified by the subscript " $\mathrm{i}$ " and " $\mathrm{j}$ ", respectively. The goal of separation bearing formation control is to achieve a control velocity such that

$$
\lim _{t \rightarrow \infty}\left(L_{i j}^{d}-L_{i j}\right)=0, \text { and } \lim _{t \rightarrow \infty}\left(\Psi_{i j}^{d}-\Psi_{i j}\right)=0,
$$

in which $L_{i j}^{d}, L_{i j}, \Psi_{i j}^{d}, \Psi_{i j}$ stands for the desired and predefined distance (or separation) to maintain to the leader, the current distance to the leader, the desired and predefined virtual angle (or bearing) to the leader and the current virtual angle, respectively.

The leader-following formation control problem can be written as one of the tree tracking control problems: trajectory tracking, path following and point stabilization e [i,i]. Considering the trajectory tracking problem, the reference WMR is replaced by the leader WMR. The leader kinematics is given by

$$
\dot{q}_{i}=\left[\begin{array}{cc}
\cos \theta_{i} & -d_{i} \sin \theta_{i} \\
\sin \theta_{i} & d_{i} \cos \theta_{i} \\
0 & 1
\end{array}\right]\left[\begin{array}{c}
v_{i} \\
\omega_{i}
\end{array}\right]+\left[\begin{array}{c}
\delta_{x_{i}} \\
\delta_{y_{i}} \\
\delta_{\theta_{i}}
\end{array}\right] .
$$

To design the follower control law, it is necessary to define the tracking controller error, in a similar manner as first proposed in $\mathrm{n}[\mathrm{a}, \mathrm{a}]$

$$
\begin{aligned}
{\left[\begin{array}{c}
e_{j_{1}} \\
e_{j_{2}} \\
e_{j_{3}}
\end{array}\right] } & =\left[\begin{array}{ccc}
\cos \theta_{j} & \sin \theta_{j} & 0 \\
-\sin \theta_{j} & \cos \theta_{j} & 0 \\
0 & 0 & 1
\end{array}\right]\left[\begin{array}{l}
x_{r}-x_{j} \\
y_{r}-y_{j} \\
\theta_{r}-\theta_{j}
\end{array}\right], \\
\dot{x}_{r} & =v_{r} \cos \theta_{r}, \dot{y}_{r}=v_{r} \sin \theta_{r}, \dot{\theta}_{r}=\omega_{r} .
\end{aligned}
$$

Then, the reference WMR can be defined as

$$
\begin{aligned}
& x_{r}=x_{i}-d_{i} \cos \theta_{i}-L_{i j}^{d} \cos \gamma_{i j}^{d} \\
& y_{r}=y_{i}-d_{i} \sin \theta_{i}-L_{i j}^{d} \sin \gamma_{i j}^{d} \\
& \theta_{r}=\theta_{i}, \\
& v_{r}=\left[\left|v_{i}\right|\left|\omega_{i}\right|\right]^{T},
\end{aligned}
$$

in which $\gamma_{i j}^{d}=\Psi_{i j}^{d}+\theta_{i}$. By the same reasoning, the position of the follower is defined as

$$
\begin{aligned}
& x_{j}=x_{i}-d_{i} \cos \theta_{i}-L_{i j} \cos \gamma_{i j} \\
& y_{j}=y_{i}-d_{i} \sin \theta_{i}-L_{i j} \sin \gamma_{i j} \\
& \theta_{j}=\theta_{j},
\end{aligned}
$$

with $\gamma_{i j}=\Psi_{i j}+\theta_{i}$.

Maximilian Jaderson de Melo, Mauricio Begnini, Heber Rabelo da Silva, and Marcelo Christiano da França Júnior Robust and adaptive chatter free formation control of wheeled mobile robots with uncertainties
ADCAIJ: Advances in Distributed Computing and Artificial Intelligence Journal Regular Issue, Vol. 7 N. 2 (2018), 27-42 elSSN: 2255-2863 - http://adcaij.usal.es Ediciones Universidad de Salamanca - CC BY NC DC 
The trajectory tracking problem consists in to reach a smooth control velocity such that the tracking controller error converges to zero. From (7) and (8) the tracking controller error can be rewritten as

$$
\left[\begin{array}{c}
e_{j 1} \\
e_{j 2} \\
e_{j 3}
\end{array}\right]=\left[\begin{array}{c}
L_{i j}^{d} \cos \gamma_{i j}^{d}-L_{i j} \cos \gamma_{i j} \\
L_{i j}^{d} \sin \gamma_{i j}^{d}-L_{i j} \sin \gamma_{i j} \\
\theta_{i}-\theta_{j}
\end{array}\right]
$$

with $\theta_{i j}=\theta_{i}-\theta_{j}$. Then, is necessary to define the system variables, introduced in (4), as

$$
\begin{aligned}
L_{x} & =x_{i}-d_{i} \cos \theta_{i}-x_{j}, \\
L_{y} & =y_{i}-d_{i} \sin \theta_{i}-y_{j}, \\
L_{i j}^{2} & =L_{x}^{2}+L_{y}^{2} \\
\Psi_{i j} & =\arctan \left(\frac{L_{y}}{L_{x}}\right)-\theta_{i}+\pi,
\end{aligned}
$$

and shown in Figure 1.

Applying the derivative of (10) in the derivative of (9), the error dynamics is found to be

$$
\left[\begin{array}{c}
\dot{e}_{j 1} \\
\dot{e}_{j 2} \\
\dot{e}_{j 3}
\end{array}\right]=\left[\begin{array}{c}
-v_{j}+v_{i} \cos \theta_{i j}+\omega_{j} e_{j 2}-\omega_{i} L_{i j}^{d} \sin \gamma_{i j}^{d} \\
-\omega_{j} e_{j 1}+v_{i} \sin \theta_{i j}-d_{j} \omega_{j}+\omega_{i} L_{i j}^{d} \cos \gamma_{i j}^{d} \\
\dot{\theta}_{j r}-\omega_{j}
\end{array}\right]
$$

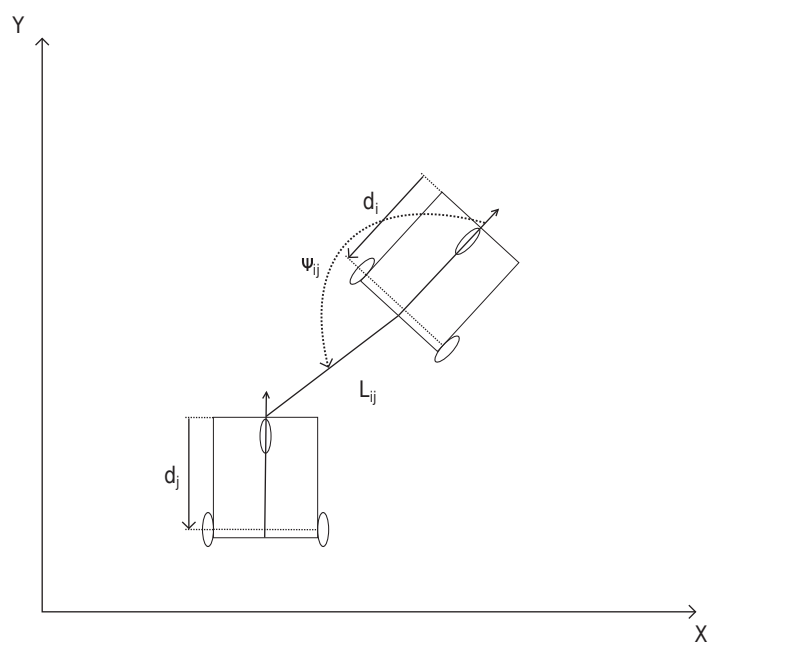

Figure 1: Separation-Bearing formation control. Adapted from e [i]

Note that in (11), $\dot{\theta}_{i}$ is replaced by $\dot{\theta}_{j r}$. This happens because of nonholonomic constraints, which does not guarantee that $\theta_{j r}=\theta_{i}$ during maneuvers. Therefore, the follower orientation relative to the leader must observe e [i]

$$
\dot{\theta}_{j r}=\frac{1}{d_{j}}\left(\omega_{i} L_{i j}^{d} \cos \gamma_{i j}^{d}+v_{i} \sin \theta_{i j r}+K_{2} e_{j 2}\right),
$$

with $\theta_{i j r}=\theta_{i}-\theta_{j r} \in[-\pi, \pi]$ and $K_{2}$ a constant positive definite. After formation errors converge to zero, $v_{i}>0$ and $\omega_{i}=0$, both leader and follower orientations will be exactly equal. 


\section{Sliding Surfaces}

The sliding mode control (SMC) is a robust feedback control with high-speed switching. This control has two phases: reaching and sliding phase. In the reaching phase, the state variables are led to a point chosen by the designer, in the state space. In the sliding phase, the state variables are forced to remain on the sliding surfaces $\mathrm{k}$ $[\mathrm{t}, \mathrm{t}] ; \mathrm{C}[\mathrm{e}]$.

From the error dynamics of (15), the sliding surfaces are selected as

$$
\begin{aligned}
& \sigma_{j}(\tilde{z}, t)=\Lambda_{j}^{T} e_{j}=\Lambda_{j}^{T} \tilde{z}=0 \\
& \sigma_{j}(\tilde{z}, t)=\left[\begin{array}{ccc}
\Lambda_{1} & 0 & 0 \\
0 & \Lambda_{2} & \Lambda_{3}
\end{array}\right]\left[\begin{array}{l}
e_{j 1} \\
e_{j 2} \\
e_{j 3}
\end{array}\right]=\left[\begin{array}{c}
\Lambda_{1} e_{j 1} \\
\Lambda_{2} e_{j 2}+\Lambda_{3} e_{j 3}
\end{array}\right],
\end{aligned}
$$

in which $\Lambda_{j}=\left[\begin{array}{lll}\Lambda_{1} & \Lambda_{2} & \Lambda_{3}\end{array}\right]^{T}$ is a positive gain matrix, which is designed in a way to force the errors to exponentially converge to zero.

According to the SMC basis theory, the error dynamics must be written in the below form

$$
\dot{\tilde{z}}=A_{0 p}+B_{0 p} u+d_{p}
$$

which allows (11) to be rewritten as

$$
\begin{array}{r}
{\left[\begin{array}{c}
\dot{e}_{j 1} \\
\dot{e}_{j 2} \\
\dot{e}_{j 3}
\end{array}\right]=\left[\begin{array}{c}
v_{i} \cos e_{j 3}-\omega_{i} L_{i j}^{d} \sin \left(\Psi_{i j}^{d}+e_{j 3}\right) \\
v_{i} \sin e_{j 3}+\omega_{i} L_{i j}^{d} \cos \left(\Psi_{i j}^{d}+e_{j 3}\right) \\
\omega_{i}
\end{array}\right]} \\
+\left[\begin{array}{cc}
-1 & e_{j 2} \\
0 & -\left(e_{j 1}+d_{j}\right) \\
0 & -1
\end{array}\right]\left[\begin{array}{c}
v_{j} \\
\omega_{j}
\end{array}\right],
\end{array}
$$

\subsection{Controller design}

Given the error dynamics in (15), is possible to formulate the Separation Bearing Sliding Mode Control (SBSMC) control law. To act in the reaching phase, $v_{j c}$ is chosen in a way to impose the desired dynamics to $\sigma_{j}(\tilde{z}, t)$ of the following first differential equation

$$
\sigma_{j}(\tilde{z}, t)=-G \operatorname{sign}\left(\sigma_{j}\right)-K \sigma_{j},
$$

in which $G=\operatorname{diag}\left[g_{1}, \ldots, g_{n}\right], K=\operatorname{diag}\left[k_{1}, \ldots, k_{n}\right]$ are positive diagonal gain matrices, $\operatorname{sign}\left(\sigma_{j}\right)=\frac{\sigma_{j}}{\left|\sigma_{j}\right|}$ is the standard signal function. Actually, in the $K \sigma_{j}=K h\left(\sigma_{j}\right)$, instead of $\sigma$ would be used any function since it satisfies $\sigma_{j}^{T} h\left(\sigma_{j}\right)$.

From (13), (15) and (16)

$$
\begin{aligned}
\dot{\sigma}_{j}(\tilde{z}, t) & =\frac{\partial \sigma_{j}(\tilde{z}, t)}{\partial \tilde{z}} \dot{\tilde{z}}+\frac{\partial \sigma_{j}(\tilde{z}, t)}{\partial t} \\
& =\frac{\partial \sigma_{j}}{\partial \tilde{z}}\left(A_{0 p}+B_{0 p} u+d_{p}\right)+\frac{\partial \sigma_{j}}{\partial t} \\
& =-\operatorname{Gsign}\left(\sigma_{j}\right)-K \sigma_{j},
\end{aligned}
$$

in which $d_{p}$ denotes the disturbances vector. From (17) the following control law is designed

$$
u=-\left(B_{0 p \sigma}\right)^{-1} A_{0 p \sigma}-\left(G \operatorname{sign}\left(\sigma_{j}\right)+K \sigma_{j}\right),
$$

Maximilian Jaderson de Melo, Mauricio Begnini, Heber Rabelo da Silva, and Marcelo Christiano da França Júnior Robust and adaptive chatter free formation control of wheeled mobile robots with uncertainties
ADCAIJ: Advances in Distributed Computing and Artificial Intelligence Journal Regular Issue, Vol. 7 N. 2 (2018), 27-42 eISSN: 2255-2863 - http://adcaij.usal.es Ediciones Universidad de Salamanca - CC BY NC DC 
with

$$
\begin{aligned}
& B_{0 p \sigma}=\frac{\partial \sigma_{j}}{\partial \tilde{z}} B_{0 p}=\left[\begin{array}{cc}
-\Lambda_{1} & \Lambda_{1} e_{j 2} \\
0 & -\Lambda_{2}\left(e_{j 1}+d_{j}\right)-\Lambda_{3}
\end{array}\right] \\
& A_{0 p \sigma}=\frac{\partial \sigma_{j}}{\partial \tilde{z}} A_{0 p}=\left[\begin{array}{c}
\Lambda_{1} v_{i} \cos e_{j 3}-\Lambda_{1} \omega_{i} L_{i j}^{d} \sin \left(\Psi_{i j}^{d}+e_{j 3}\right) \\
\Lambda_{2} v_{i} \sin e_{j 3}+\Lambda_{2} \omega_{i} L_{i j}^{d} \cos \left(\Psi_{i j}^{d}+e_{j 3}\right)+\omega_{i} \Lambda_{3}
\end{array}\right] \\
& B_{0 p \sigma}^{-1}=\left[\begin{array}{cc}
-\frac{1}{\Lambda_{1}} & -\frac{\Lambda_{2}}{\Lambda_{2}\left(e_{j 1}+d_{j}\right)+\Lambda_{3}} \\
0 & -\frac{1}{\Lambda_{1}\left(e_{j 1}+d_{j}\right)+\Lambda_{3}}
\end{array}\right]
\end{aligned}
$$

Substituting (18) in (17), leads to

$$
\begin{aligned}
\dot{\sigma}_{j}(\tilde{z}, t) & =A_{0 p \sigma_{j}}-B_{0 p \sigma_{j}}^{-1}\left(A_{0 p \sigma_{j}}+G \operatorname{sign}\left(\sigma_{j}\right)+K \sigma_{j}\right)+d_{\sigma} \\
& =-G \operatorname{sign}\left(\sigma_{j}\right)-K \sigma_{j}+d_{\sigma}
\end{aligned}
$$

in which $d_{\sigma}=\frac{\partial \sigma_{j}}{\partial \tilde{z}} d_{p}$.

\subsection{Satability analysis}

Considering the following Lyapunov candidate function

$$
V=\frac{1}{2} \sigma_{j}^{T} \sigma_{j}
$$

which is clearly positive definite. Then, the sliding surface is attractive since the control law, described in (18), assures that

$$
\begin{aligned}
\dot{V} & =\sigma_{j}^{T} \dot{\sigma}_{j} \\
& =-\sigma_{j}^{T} G \operatorname{sign}\left(\sigma_{j}\right)-\sigma_{j}^{T} K \sigma_{j}+d_{\sigma} .
\end{aligned}
$$

Since $\sigma_{j}^{T} \mathbf{K} \sigma_{j} \geq 0$ and $\sigma_{j}^{T} \mathbf{G} \operatorname{sign}\left(\sigma_{j}\right) \geq d_{\sigma}$ then $\dot{V} \leq 0$, which is satisfied since $g_{i} \leq\left|d_{\sigma}\right|$, where $g_{i}$ is the minimum singular value (MSV) of $\mathbf{G}$ while $d_{\sigma}$ represents the maximum value of the uncertainties/disturbances.

The reachability of the sliding mode is guaranteed if $\dot{V} \leq 0$, that depends on $B_{0 p \sigma}$ to be nonsingular, definite positive and $\mathbf{G}$ is large enough. In the other hand, $B_{0 p \sigma}$ is only guaranteed to be nonsingular. To guaranteed the reachability, a diagonalization method is applied to design a new sliding surface $\mathrm{r}$ [a]

$$
\sigma_{j}^{*}(\tilde{z}, t)=\xi(\tilde{z}, t) \sigma_{j}(\tilde{z}, t)=\xi(\tilde{z}, t) \Lambda^{T} \tilde{z}
$$

in which $\xi(\tilde{z}, t) \in \mathbb{R}^{n \times n}$ is a nonsingular suitable transformation. Given that $\sigma_{j}(\tilde{z}, t) \rightarrow 0$, then the sliding mode is invariant to the sliding surfaces transformation if $\|\dot{\xi}\|$ and $\left\|\xi^{-1}\right\|$ are bounded for all $t, \tilde{z} \in \Lambda \subseteq \mathbb{R} \times \mathbb{R}^{n}$ $\mathrm{C}[\mathrm{e}]$. The transformation is defined as

$$
\xi(\tilde{z}, t)\left(\frac{\partial \sigma}{\partial \tilde{z}} B\right)^{T}=B_{0 p \sigma}^{T} .
$$

With the new surfaces, the proof of $\dot{V}$ becomes

$$
\begin{aligned}
\dot{V} & =+\sigma_{j}^{T} \dot{\sigma}_{j} \\
& =\sigma_{j}^{*^{T}} B_{0 p \sigma}^{-1}\left(A_{0 p \sigma_{j}}\right)+\sigma_{j}^{*^{T}}\left(u+d_{\sigma}\right),
\end{aligned}
$$

which leads to select the new control law

$$
u=-\left(B_{0 p \sigma}\right)^{-1}\left(A_{0 p \sigma}+G \operatorname{sign}\left(\sigma_{j}^{*}\right)+K \sigma_{j}^{*}\right),
$$

Maximilian Jaderson de Melo, Mauricio Begnini, Heber Rabelo da Silva, and Marcelo Christiano da França Júnior Robust and adaptive chatter free formation control of wheeled mobile robots with uncertainties
ADCAIJ: Advances in Distributed Computing and Artificial Intelligence Journal Regular Issue, Vol. 7 N. 2 (2018), 27-42 elSSN: 2255-2863 - http://adcaij.usal.es Ediciones Universidad de Salamanca - CC BY NC DC 
substituting (26) in (25), a final expression is obtained as

$$
\dot{V}=-\sigma_{j}^{*^{T}}\left(G \operatorname{sign}\left(\sigma_{j}^{*}\right)+K \sigma_{j}^{*}\right)+\sigma_{j}^{*^{T}} d_{\sigma} .
$$

The (27) is similar to (22), therefore the prior analysis is still valid. Also, the transformation guarantees $B_{0 p \sigma}$ as non-singular and positive definite. The manifolds $\sigma_{j}(\tilde{z}, t)=0$ and $\sigma_{j}^{*}(\tilde{z}, t)=0$ coincide, $\sigma_{j}^{*} \rightarrow 0$ and the sliding mode occurs when $\sigma_{j}^{*}=0$.

\subsection{Chattering attenuation}

The SBSMC presents high speed and low amplitude chattering in the sliding surfaces. This fact influences directly in the velocities applied in the WMR and due to physical limitations it is not applicable in real implementations $r$ [a]. This phenomenon occurs because of the discontinuous parcel $\mathbf{G} \operatorname{sign}\left(\sigma_{j}^{*}\right)$ of the controller. The chattering can cause excessive wear on actuators $\mathrm{k}$ [t]. The phenomenon can be reduced replacing the discontinuous parcel by a continuous approximation.

To solve the chattering problem, an Adaptive Fuzzy Separation Bearing Sliding Mode Controller (AFSBSMC) is proposed.

\section{Adaptive fuzzy separation-bearing sliding mode controller}

The AFSBSMC is a controller intended to present a linear approximation based on fuzzy logic to reduce the chattering effect. This controller aims to maintain the controller robustness even without the knowledge of the uncertainties/ disturbances bounds.

In fuzzy logic, the system is composed by four components: fuzzification, fuzzy knowledge base, fuzzy inference machine and deffuzification. The system is shown in the Figure 2. For a more detailed description of fuzzy logic and fuzzy logic controllers can be seen in a $[\mathrm{h}]$.

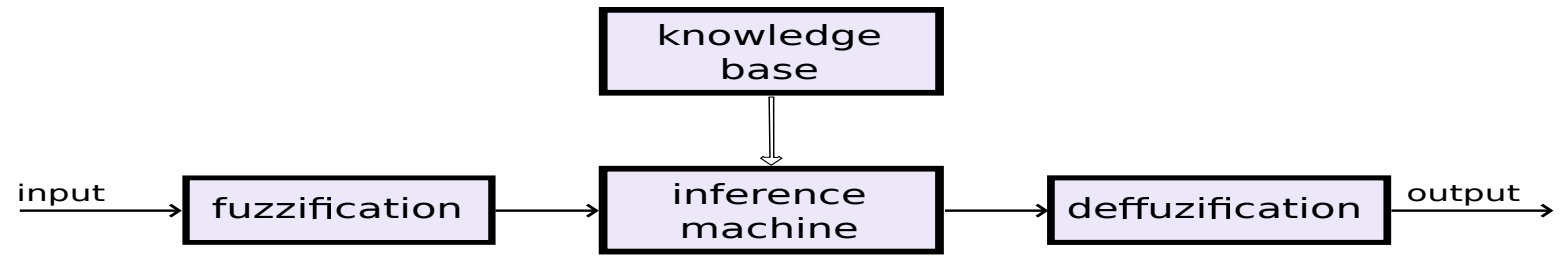

Figure 2: Block diagram of a generic fuzzy system.

In this paper, the controller is based on singleton fuzzification method, the Takagi-Sugeno-Kang (TSK) inference machine, defuzzification by center of mass $n$ [a]. Given a input " $x "$, the output " $y$ " can be defined as

$$
y=\frac{\sum_{m=1}^{M} \theta_{m} \prod_{i=1}^{n} \mu_{A_{i}^{m}}\left(x_{i}^{*}\right)}{\sum_{m=1}^{M} \prod_{i=1}^{n} \mu_{A_{i}^{m}}\left(x_{i}^{*}\right)}=\theta^{T} \Psi(x)
$$

in which $\theta=\left[\theta^{1} \ldots ; \theta^{M}\right]^{T}$ represents the vector of centers of membership functions, $\Psi(x)=\left[\Psi(x)^{1} \ldots ; \Psi(x)^{M}\right]^{T}$ represents the vector of membership function weights, $\mu_{A}$ represents the membership function to rule $A$ and $M$ the rule number.

Maximilian Jaderson de Melo, Mauricio Begnini, Heber Rabelo da Silva, and Marcelo Christiano da França Júnior Robust and adaptive chatter free formation control of wheeled mobile robots with uncertainties
ADCAIJ: Advances in Distributed Computing and Artificial Intelligence Journal Regular Issue, Vol. 7 N. 2 (2018), 27-42 eISSN: 2255-2863 - http://adcaij.usal.es Ediciones Universidad de Salamanca - CC BY NC DC 


\subsection{Controller design}

The chattering in the control law given in (18) is caused by the $G \operatorname{sign}\left(\sigma_{j}^{*}\right)$ discontinuous parcel. Therefore, this parcel is replaced by a linear parcel $\hat{F}\left(\sigma_{j}^{*}\right)$ based on fuzzy logic. The control law becomes

$$
u=-\left(B_{0 p \sigma}\right)^{-1} A_{0 p \sigma}-\left(\hat{F}\left(\sigma_{j}^{*}\right)+K \sigma_{j}\right),
$$

in which $\hat{F}\left(\sigma_{j}^{*}\right)=\left[\hat{f}_{1}\left(\sigma_{j}^{*}\right) \ldots \hat{f}_{n}\left(\sigma_{j}^{*}\right)\right]^{T}$, which each $\hat{f}\left(\sigma_{j}^{*}\right)$ is estimated by a fuzzy system, according to (28).

To update the parameters of membership functions of $f_{j}\left(\sigma_{j}^{*}(\tilde{z}, t)\right), \theta_{f_{j}}$ is selected. Defining $\hat{\theta}_{f_{j}}$ in a way that $f_{j}=\hat{\theta}_{f_{j}} \Psi_{f_{j}}\left(\sigma_{j}(\tilde{z}, t)\right)$ becomes the optimal compensation for $\mathrm{Y}_{j}$. According to $\mathrm{u}$ [i], exists a $\epsilon_{j}>0$ such that

$$
\left|\tilde{d}_{o_{j}}-\theta_{f_{j}}^{T} \Psi_{f_{j}}\left(\sigma_{j}(\tilde{z}, t)\right)\right| \leq \epsilon_{j}, \mathrm{Y}=\Delta f
$$

which $\epsilon_{j}$ is the lowest possible value. The error estimation is defined as

$$
\tilde{\theta}_{f_{j}}=\hat{\theta}_{f_{j}}-\theta_{f_{j}}
$$

Therefore, (28) can be rewritten as

$$
\hat{f}_{j}\left(\sigma_{j}^{*}(\tilde{z}, t)\right)=\tilde{\theta}_{f_{j}}^{T} \Psi_{f_{j}}\left(\sigma_{j}^{*}(\tilde{z}, t)\right)+\theta_{f_{j}}^{T} \Psi_{f_{j}}\left(\sigma_{j}^{*}\right) .
$$

Then, the adaptive control law is given by

$$
\dot{\tilde{\theta}}_{f_{j}}=\dot{\hat{\theta}}_{f_{j}}=\sigma_{j}^{*} \Psi_{f_{j}}\left(\sigma_{j}^{*}\right)
$$

\subsection{Controller knowledge base rules}

To decide the knowledge base rules, similarly to u [i], the Lyapunov candidate function, in (37) was analyzed. $V$ is an energy indicator of $\sigma_{j}^{*}(\tilde{z}, t)$. The system stability is reached selecting a control law that grantees $\dot{V} \leq 0$. To this controller, $\hat{F}\left(\sigma_{j}^{*}(\tilde{z}, t)\right)$ is applied to compensate uncertainties/disturbances, reduce chattering effects and reduce the energy of $\sigma_{j}^{*}(\tilde{z}, t)$.

$$
\dot{V}=\sum_{i=1}^{n}\left(\sigma_{j}^{*}(\tilde{z}, t)\left(d_{\sigma}-f_{j}^{i}\left(\sigma_{j}^{*}(\tilde{z}, t)\right)\right)\right)-\sigma_{j}^{*}(\tilde{z}, t) K \sigma_{j}^{*}(\tilde{z}, t) .
$$

Once $\operatorname{sign}\left(\sigma_{j}^{*}(\tilde{z}, t)\right)$ has the same signal of $\sigma_{j}^{*}(\tilde{z}, t), f_{j}\left(\sigma_{j}^{*}(\tilde{z}, t)\right)$ also must have the same signal. If $\sigma_{j}^{*}(\tilde{z}, t)$ is very large, $f_{j}\left(\sigma_{j}^{*}(\tilde{z}, t)\right)$ also must be large, so $\dot{V}$ will have a big negative value and, thus, $\sigma_{j}^{*}(\tilde{z}, t)$ value will decrease quickly. If $\sigma_{j}^{*}(\tilde{z}, t)$ has a small value, then $\left(\sigma_{j}^{*}(\tilde{z}, t)\left(d_{\sigma}-f_{j}\left(\sigma_{j}^{*}(\tilde{z}, t)\right)\right.\right.$ is also small, with little influence in $\dot{V}$, which means that $f_{j}\left(\sigma_{j}^{*}(\tilde{z}, t)\right)$ has also a small value, reducing chattering occurrence. If $\sigma_{j}^{*}(\tilde{z}, t)=0$, then $\left(\sigma_{j}^{*}(\tilde{z}, t)\left(d_{\sigma}-f_{j}\left(\sigma_{j}^{*}(\tilde{z}, t)\right)=0\right.\right.$, thus, $f_{j}\left(\sigma_{j}^{*}(\tilde{z}, t)\right)$ shall be zero, as formulated in u [i].

In this paper, the membership functions are the same both to input $\sigma_{v}^{*}, \sigma_{\omega}^{*}$ and output $f_{j}\left(\sigma_{v}^{*}\right), f_{j}\left(\sigma_{\omega}^{*}\right)$. The membership are chosen as triangular functions, and are described below

$$
\mu_{A}\left(x_{j}\right)= \begin{cases}0, & x<i \\ \frac{x_{j}-i}{j-i}, & i \leq x_{j} \leq j \\ \frac{k-x_{j}}{k-j}, & j \leq x_{j} \leq k \\ 0, & k<x_{j}\end{cases}
$$

in which $A$ represents one of the fuzzy sets, $x_{j}$ represents $\sigma_{j}^{*}(\tilde{z}, t)$ or $f_{j}\left(\sigma_{j}^{*}(\tilde{z}, t)\right), i, k, j$ represents the bases and the peak of the functions, respectively. The parameters $\sigma_{j_{v}}^{*}, \sigma_{j_{\omega}}^{*}$ are shown in Table 1.

Maximilian Jaderson de Melo, Mauricio Begnini, Heber Rabelo da Silva, and Marcelo Christiano da França Júnior Robust and adaptive chatter free formation control of wheeled mobile robots with uncertainties
ADCAIJ: Advances in Distributed Computing and Artificial Intelligence Journal Regular Issue, Vol. 7 N. 2 (2018), 27-42 elSSN: 2255-2863 - http://adcaij.usal.es Ediciones Universidad de Salamanca - CC BY NC DC 
The controller is defined as

$$
f_{j}\left(\sigma_{j}^{*}(\tilde{z}, t)\right)=\frac{\sum_{m=1}^{M} \theta_{m} \mu_{A_{j}^{m}}\left(\sigma_{j}^{*}(\tilde{z}, t)\right)}{\sum_{m=1}^{M} \mu_{A_{j}^{m}}\left(\sigma_{j}^{*}(\tilde{z}, t)\right)}=\theta_{f_{j}}^{T} \Psi_{f_{j}}\left(\sigma_{j}^{*}(\tilde{z}, t)\right),
$$

which $\theta_{f_{j}}=\left[\theta_{f_{j}}^{1}, \ldots, \theta_{f_{j}}^{M}\right]^{T}$ is the vector of centers of mass of the membership functions, $\Psi_{f_{j}}\left(\sigma_{j}^{*}(\tilde{z}, t)\right)=$ $\left[\Psi_{f_{j}}^{1}\left(\sigma_{j}^{*}(\tilde{z}, t)\right), \ldots, \Psi_{f_{j}}^{M}\left(\sigma_{j}^{*}(\tilde{z}, t)\right)\right]^{T}$ represents the vector of weights of the membership functions and $M$ is the number of rules.

Table 1: Membership functions parameters of $\sigma_{j_{v}}^{*}, \sigma_{j_{\omega}}^{*}$

\begin{tabular}{c|ccc|ccc}
\hline & \multicolumn{3}{|c|}{$\sigma_{j_{v}}^{*}$} & \multicolumn{3}{c}{$\sigma_{j_{\omega}}^{*}$} \\
\hline & $\mathrm{i}$ & $\mathrm{j}$ & $\mathrm{k}$ & $\mathrm{i}$ & $\mathrm{j}$ & $\mathrm{k}$ \\
\hline $\mathrm{NB}$ & $-\infty$ & -0.5 & -0.33 & $-\infty$ & -0.7 & -0.47 \\
$\mathrm{NM}$ & -0.5 & -0.33 & -0.16 & -0.7 & -0.47 & -0.23 \\
NS & -0.33 & -0.16 & 0 & -0.47 & -0.23 & 0 \\
$\mathrm{ZE}$ & -0.16 & 0 & 0.16 & -0.23 & 0 & 0.23 \\
PS & 0 & 0.16 & 0.33 & 0 & 0.23 & 0.47 \\
PM & 0.16 & 0.33 & 0.5 & 0.23 & 0.47 & 0.7 \\
PB & 0.33 & 0.55 & $\infty$ & 0.47 & 0.7 & $\infty$ \\
\hline
\end{tabular}

\subsection{Stability analysis}

Consider the following Lyapunov candidate function

$$
V=\frac{1}{2}\left(\sigma_{j}^{T} \sigma_{j}+\sum_{i=1}^{n} \tilde{\theta}_{f_{i}}^{T} \tilde{\theta}_{f_{i}}\right)
$$

in which $V$ is positive definite, once $\tilde{\theta}_{f_{i}}^{T} \tilde{\theta}_{f_{i}}>0$. Differentiating $V$ leads to

$$
\begin{aligned}
\dot{V} & =\sigma_{j}^{T} \dot{\sigma}_{j}+\sum_{i=1}^{n} \tilde{\theta}_{f_{i}}^{T} \dot{\tilde{\theta}}_{f_{i}} \\
& =-\sigma_{j}^{T} A_{0 p \sigma}+\sigma_{j}^{T} B_{0 p \sigma} u+\sigma_{j}^{T} B_{0 p \sigma}\left(d_{\sigma}\right)+\sum_{i=1}^{n} \tilde{\theta}_{f_{i}}^{T} \dot{\tilde{\theta}}_{f_{i}} \\
& =\left(B_{0 p \sigma}^{T} \sigma_{j}\right)^{T} B_{0 p \sigma}^{-1}\left(A_{0 p \sigma}\right)+\left(B_{0 p \sigma}^{T} \sigma\right)^{T}\left(u+d_{\sigma}\right)+\sum_{i=1}^{n} \tilde{\theta}_{f_{i}}^{T} \dot{\tilde{\theta}}_{f_{i}} \\
& =\sigma_{j}^{*^{T}} B_{0 p \sigma}^{-1}\left(A_{0 p \sigma}\right)+\sigma_{j}^{*^{T}}(u+\tilde{d})+\sum_{i=1}^{n} \tilde{\theta}_{f_{i}}^{T} \dot{\tilde{\theta}}_{f_{i}} .
\end{aligned}
$$

Substituting the control law in (38)

$$
\begin{array}{r}
\dot{V}=-\sigma_{j}^{*^{T}} \tilde{\theta}_{f_{j}}^{T} \Psi_{f_{j}}\left(\sigma_{j}^{*}\right)-\sigma_{j}^{*^{T}} \theta_{f_{j}}^{T} \Psi_{f_{j}}\left(\sigma_{j}^{*}\right)-K \sigma_{j}^{*} \\
+\sigma_{j}^{*^{T}} \Delta f_{j}+\sum_{i=1}^{n} \tilde{\theta}_{f_{i}}^{T} \dot{\tilde{\theta}}_{f_{i}} .
\end{array}
$$

Maximilian Jaderson de Melo, Mauricio Begnini, Heber Rabelo da Silva, and Marcelo Christiano da França Júnior Robust and adaptive chatter free formation control of wheeled mobile robots with uncertainties
ADCAIJ: Advances in Distributed Computing and Artificial Intelligence Journal Regular Issue, Vol. 7 N. 2 (2018), 27-42 elSSN: 2255-2863 - http://adcaij.usal.es Ediciones Universidad de Salamanca - CC BY NC DC 
Applying (30) results in

$$
\dot{V}=-K \sigma_{j}^{*}+\sum_{i=1}^{n} \sigma_{j}^{*}\left(\Delta f_{i}-\theta_{f_{i}}^{T} \Psi_{f_{i}}\left(\sigma_{j}^{*}\right)\right)
$$

with

$$
\left|\Delta f_{i}-\theta_{f_{i}}^{T} \Psi_{f_{i}}\left(\sigma_{j}\right)\right| \leq \epsilon_{j} \leq \gamma_{i}\left|\sigma_{j}^{*}\right|
$$

which $\left|\gamma_{i}\right|<1$. This way, the right side of (41) satisfies

$$
\sigma_{j}^{*}\left|\Delta f_{i}-\theta_{f_{i}}^{T} \Psi_{f_{i}}\left(\sigma_{j}\right)\right| \leq \gamma_{i}\left|\sigma_{j}^{*}\right|^{2}=\gamma_{i} \sigma_{j}^{*^{2}}
$$

and therefore

$$
\dot{V}=-K \sigma_{j}^{*}+\Xi_{j},
$$

in which $\Xi_{j}$ is defined as

$$
\Xi_{j}=\sum_{i=0}^{n}\left(-k_{i}{\sigma_{j}^{*}}^{2}+\gamma_{i}{\sigma_{j}^{2}}^{2}\right)=-\sigma^{T}(A-\gamma) \sigma_{j}^{*} \leq 0,
$$

which $\gamma=\operatorname{diag}\left[\gamma_{1}, \ldots, \gamma_{n}\right]$. Selecting $k_{i}-\gamma_{i}$, with the matrix $(K-\gamma)$ positive definite, $-\sigma^{T}(K-\gamma) \sigma^{*} \leq 0$. Consequently $\dot{V} \leq 0$ e $\dot{V}=0$ if and only if $\sigma_{j}^{*}=0$. Thus, the system is asymptotically stable.

\section{Simulation results}

A wedge of four identical WMRs were considered. The eight-shaped tracking trajectory was chosen to formation control. The WMRs were named as $\mathrm{i}, \mathrm{j}, \mathrm{k}, \mathrm{l}$. The WMR $\mathrm{i}$ acted as a leader to $\mathrm{j}$ and $\mathrm{k}$ WMRs, while $\mathrm{k}$ acted as a leader to the WMR 1 . The entire controllers formulation are generic for each follower. the WMR i formulation was used based on $\mathrm{g}$ [e]. The wedge formation is shown in Figure 3.

The simulations were made with 160 seconds each, using a fixed-step of $0.005 \mathrm{~s}$ seconds. There were analyzed two scenarios: pure kinematics only and kinematic with disturbances. The results are shown below.

\subsection{Pure kinematic results}

The controllers presented in (18) and (29) was simulated based on the kinematic models given in (1). The kinematic parameters were $\Lambda_{j 1}=5, \Lambda_{j 2}=5, \Lambda_{j 3}=0.2, K_{11 j}=0.01, K_{22 j}=0.01, G_{11 j}=0.01$, $G_{22 j}=0.01, \Lambda_{i 1}=1, \Lambda_{i 2}=6, \Lambda_{i 3}=1, K_{11 i}=0.1, K_{22 i}=0.1, G_{11 i}=1, G_{22 i}=1, d=0.25 \mathrm{~m}$.

Maximilian Jaderson de Melo, Mauricio Begnini, Heber Rabelo da Silva, and Marcelo Christiano da França Júnior Robust and adaptive chatter free formation control of wheeled mobile robots with uncertainties
ADCAIJ: Advances in Distributed Computing and Artificial Intelligence Journal Regular Issue, Vol. 7 N. 2 (2018), 27-42 eISSN: 2255-2863 - http://adcaij.usal.es Ediciones Universidad de Salamanca - CC BY NC DC 


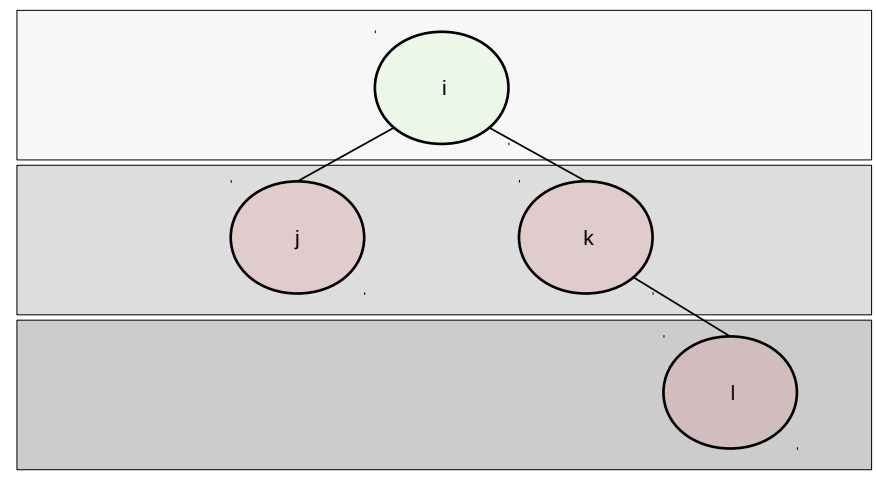

Figure 3: Formation wedge.

Figure 4, shows the formation control executed considering only the kinematics. The reference trajectory was drawn in blue, the main leader was drawn in green. To the followers, the ones who used SBSMC were drawn in black and the ones who used AFSBSBC were drawn in red. Observing this figure, SBSMC had small issues to WMRs $\mathrm{j}$ and 1 in the simulation beginning, but after stabilization, both controllers had similar responses.

Observing the errors in Figure 5(a) and 5(b), both controllers has similar responses after stabilization. Before stabilization, AFSBSMC had more accurate responses.

In Figure 6(a) and 6(b) the chattering phenomenon is visible in SBSMC to all WMRs, especially to WMR j, with high peaks both in linear and angular velocities. In AFSBSMC, the phenomenon is not present, as expected.

Analyzing the Root Mean Square (RMS) described in Table 2 of formation control error variables it is evident that the error was small and acceptable for both SBSMC and AFSBSMC, with precision in the order of $10^{-2}$ but AFSBSMC had smaller errors.

Table 2: RMS of formation control error.

\begin{tabular}{cccc|cccc}
\hline \multicolumn{4}{c}{ SBSMC } & \multicolumn{4}{c}{ AFSBSMC } \\
\hline j - L: & 0,037 & $\mathbf{j}-\Psi:$ & 0,086 & $\mathbf{j}-\mathbf{L}:$ & 0.027 & $\mathbf{j}-\Psi$ & 0,044 \\
$\mathbf{k}-\mathbf{L}:$ & 0,057 & $\mathbf{k}-\Psi:$ & 0,021 & $\mathbf{k}-\mathbf{L}:$ & 0,037 & $\mathbf{k}-\Psi:$ & 0,017 \\
$\mathbf{l}$ - L: & 0,083 & $\mathbf{l}-\Psi:$ & 0,026 & $\mathbf{l}$ - L: & 0,035 & $\mathbf{l}-\Psi:$ & 0,006 \\
\hline
\end{tabular}

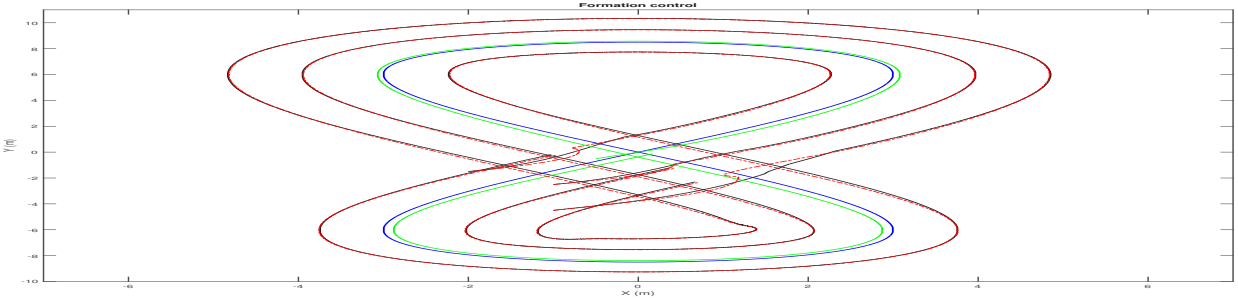

Figure 4: Formation control.

Maximilian Jaderson de Melo, Mauricio Begnini, Heber Rabelo da Silva, and Marcelo Christiano da França Júnior Robust and adaptive chatter free formation control of wheeled mobile robots with uncertainties
ADCAIJ: Advances in Distributed Computing and Artificial Intelligence Journal Regular Issue, Vol. 7 N. 2 (2018), 27-42 eISSN: 2255-2863 - http://adcaij.usal.es Ediciones Universidad de Salamanca - CC BY NC DC 


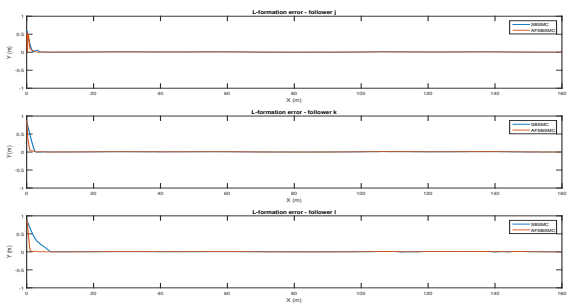

(a) Formation error in L.

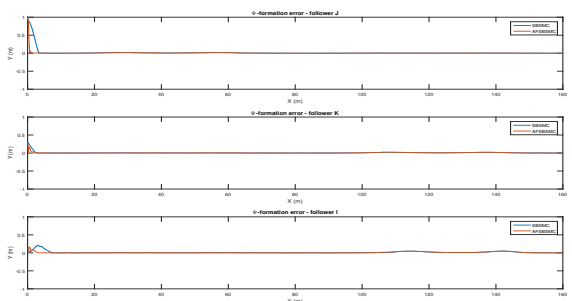

(b) Formation error in $\Psi$.

Figure 5: Formation errors

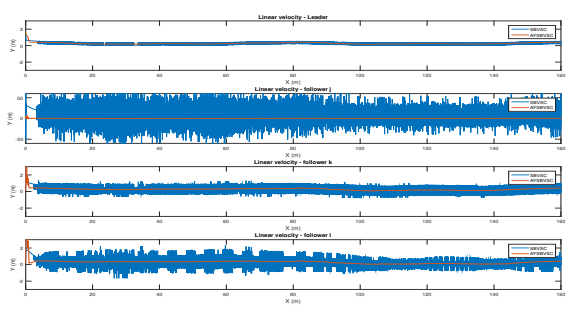

(a) Linear velocities

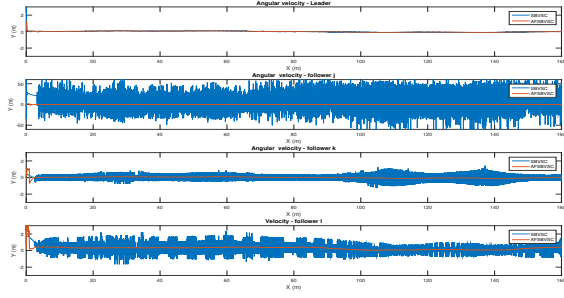

(b) Angular velocities.

Figure 6: WMR velocities

\subsection{Simulation with kinematic disturbances}

The disturbance vector is defined similarly in $\mathrm{r}[\mathrm{o}]$; $\mathrm{x}$ [i], and is formulated as

$$
\begin{aligned}
\delta_{x}= & \rho_{1}=\alpha \cos \theta, \\
\delta_{y}= & \rho_{2}=\alpha \sin \theta, \\
\delta_{\theta}= & \rho_{3}=0, \\
\alpha= & {[0.03 H(t-12)-0.03 H(t-37)-0.05 H(t-70)} \\
& -0.05 H(t-81)-0.5 H(t-90)-0.05 H(t-105)],
\end{aligned}
$$

in which $H$ is the standard Heaviside function.

Figure 7, shows the formation control executed. the WMRs were plotted with the same logic as in the previously scenario. Observing this figure, SBSMC had small issues in the internal curve, with one WMR, evidencing the effect of string errors.

Observing the errors of Figure 8(a) and 8(b), one can see that the WMR 1 presented low magnitude errors in $\Psi$. It is perceptible that the errors can be removed by increasing the $K 4(K)$ gain. It is also perceptible the advantages of AFSBSMC, since it compensated the disturbances effects without any previous knowledge about their bounds.

In both velocities, in Figure 9(a) and 9(b), the chattering phenomenon still appears in SBSMC. In AFSBSMC, the velocities are smooth and applicable in a real environment.

Finally, observing the RMS's exposed in Table 3 of formation control error variables, one can see that the error was small and acceptable for both SBSMC and AFSBSMC, but AFSBSMC presented smaller average errors.

Maximilian Jaderson de Melo, Mauricio Begnini, Heber Rabelo da Silva, and Marcelo Christiano da França Júnior Robust and adaptive chatter free formation control of wheeled mobile robots with uncertainties
ADCAIJ: Advances in Distributed Computing and Artificial Intelligence Journal Regular Issue, Vol. 7 N. 2 (2018), 27-42 eISSN: 2255-2863 - http://adcaij.usal.es Ediciones Universidad de Salamanca - CC BY NC DC 
Table 3: RMS of formation control error.

\begin{tabular}{cccc|cccc}
\hline \multicolumn{4}{c}{ SBSMC } & \multicolumn{4}{c}{ AFSBSMC } \\
\hline j - L: & 0,038 & $\mathbf{j}-\Psi:$ & 0,082 & $\mathbf{j}-\mathbf{L}:$ & 0.030 & $\mathbf{j}-\Psi$ & 0,045 \\
$\mathbf{k}-\mathbf{L}:$ & 0,053 & $\mathbf{k}-\Psi:$ & 0,016 & $\mathbf{k}-\mathbf{L}:$ & 0,035 & $\mathbf{k}-\Psi:$ & 0,012 \\
$\mathbf{l}-\mathbf{L}:$ & 0,091 & $\mathbf{l}-\Psi:$ & 0,036 & $\mathbf{l}-\mathbf{L}:$ & 0,044 & $\mathbf{l}-\Psi:$ & 0,012 \\
\hline
\end{tabular}

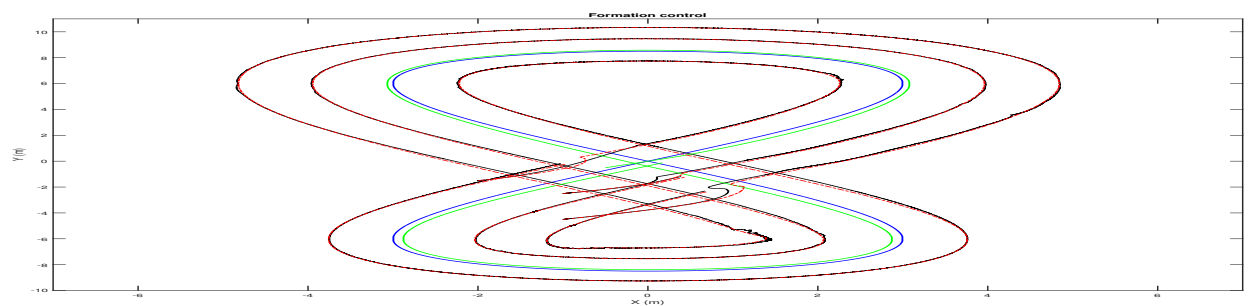

Figure 7: Formation control.

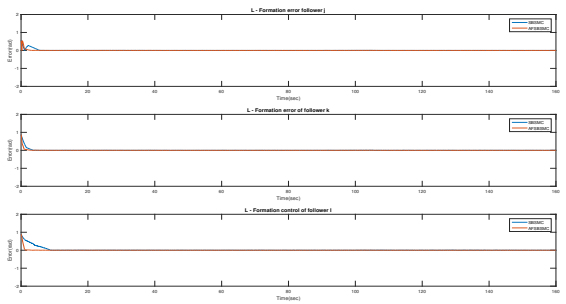

(a) Formation error in L.
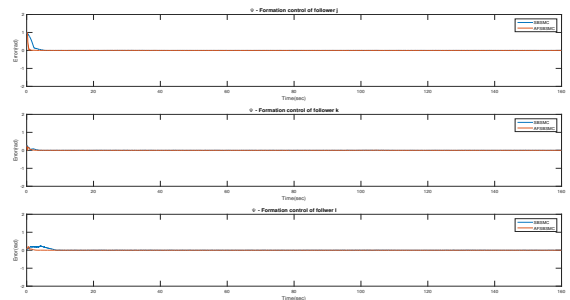

(b) Formation error in $\Psi$.

Figure 8: Formation errors

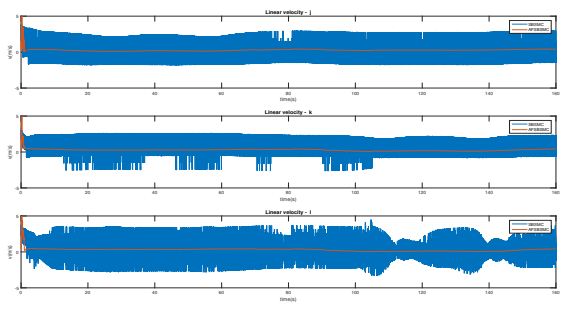

(a) Linear velocities.

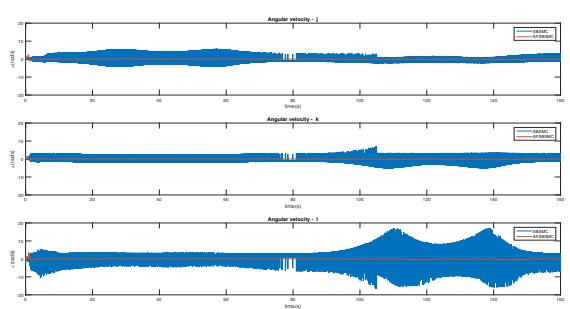

(b) Angular velocities.

Figure 9: WMR velocities

Maximilian Jaderson de Melo, Mauricio Begnini, Heber Rabelo da Silva, and Marcelo Christiano da França Júnior Robust and adaptive chatter free formation control of wheeled mobile robots with uncertainties
ADCAIJ: Advances in Distributed Computing and Artificial Intelligence Journa Regular Issue, Vol. 7 N. 2 (2018), 27-42 elSSN: 2255-2863 - http://adcaij.usal.es Ediciones Universidad de Salamanca - CC BY NC DC 


\section{Conclusion}

In this paper, the kinematic controller AFSBSMC was proposed as a solution to formation control problem. To evince the controller efficiency, SBSMC and AFSBSMC were compared in a trajectory tracking problem of a eight-shaped trajectory.

The SMC was considered because of its robustness. The SMC main disadvantage are the chattering phenomenon, which is not desirable in a real system and the previous need of knowledge of the disturbances bounds. To eliminate chattering as well as automatically tune controller gains for optimal responses in environments which disturbances/uncertainties with any bounding may occur, the AFSBSMC were considered. The results showed that in comparison with SBSMC, the AFSBSMC compensated the disturbances/uncertainties added individually in the kinematics and the chattering effect were completely removed for all simulations performed. The results also showed that errors in AFSBSMC converges to zero faster than SBSMC.

The stability analysis with both SMC and adaptive fuzzy system were proved with Lyapunov Theory.

For future works, the experimentation in real environments is aimed. There are two another works in progress: consider static/dynamic obstacle avoidance and add the WMR dynamics and actuator dynamics to the control design. Lastly, the control design of formation control with quad-rotors in the squad is aimed.

\section{Acknowledgements}

This research was supported by CAPES.

\section{References}

Begnini, M., Bertol, D. W., and Martins, N. A., 2015. VALIDATION OF A SIMPLE AND EFFECTIVE ROBUST ADAPTIVE FUZZY VARIABLE STRUCTURE TRACKING CONTROL FOR THE WHEELED

MOBILE ROBOT. International Journal of Innovative Computing, Information and Control.

Chatraei, A. and Javidian, H., 2015. Formation control of mobile robots with obstacle avoidance using fuzzy artificial potential field. In Electronics, Control, Measurement, Signals and their Application to Mechatronics (ECMSM), 2015 IEEE International Workshop of, pages 1-6. doi:10.1109/ECMSM.2015.7208710.

Chen, Y.-Q. and Wang, Z., 2005. Formation control: a review and a new consideration. In Intelligent Robots and Systems, 2005. (IROS 2005). 2005 IEEE/RSJ International Conference on, pages 3181-3186. doi: 10.1109/ IROS.2005.1545539.

Corradini, M. L., Leo, T., and Orlando, G., 1999. Robust stabilization of a mobile robot violating the nonholonomic constraint via quasi-sliding modes. In Proceedings of the 1999 American Control Conference (Cat. No. 99CH36251), volume 6, pages 3935-3939 vol.6. ISSN 0743-1619. doi:10.1109/ACC.1999.786255.

DeCarlo, R. A., Zak, S. H., and Matthews, G. P., 1988. Variable structure control of nonlinear multivariable systems: a tutorial. Proceedings of the IEEE, 76(3):212-232.

Dierks, T. and Jagannathan, S., 2007. Control of Nonholonomic Mobile Robot Formations: Backstepping Kinematics into Dynamics. In Control Applications, 2007. CCA 2007. IEEE International Conference on, pages 94-99. doi:10.1109/CCA.2007.4389212.

Dierks, T. and Jagannathan, S., 2009. Neural Network Control of Mobile Robot Formations Using RISE Feedback. IEEE Transactions on Systems, Man, and Cybernetics, Part B (Cybernetics), 39(2):332-347. ISSN 1083-4419. doi:10.1109/TSMCB.2008.2005122.

Dixon, W., Dawson, D., and Zergeroglu, E., 2000. Tracking and regulation control of a mobile robot system with kinematic disturbances: A variable structure-like approach. Journal of Dynamic Systems, Measurement, and Control, 122(4):616-623.

Fierro, R. and Lewis, F., 1995. Control of a nonholonomic mobile robot: backstepping kinematics into dynamics. In Decision and Control, 1995., Proceedings of the 34th IEEE Conference on, volume 4, pages 3805-3810 vol.4. ISSN 0191-2216. doi:10.1109/CDC.1995.479190.

Maximilian Jaderson de Melo, Mauricio Begnini, Heber Rabelo da Silva, and Marcelo Christiano da França Júnior Robust and adaptive chatter free formation control of wheeled mobile robots with uncertainties
ADCAIJ: Advances in Distributed Computing and Artificial Intelligence Journal Regular Issue, Vol. 7 N. 2 (2018), 27-42 eISSN: 2255-2863 - http://adcaij.usal.es Ediciones Universidad de Salamanca - CC BY NC DC 
Kamel, M. A. and Zhang, Y., 2015. Decentralized leader-follower formation control with obstacle avoidance of multiple unicycle mobile robots. In 2015 IEEE 28th Canadian Conference on Electrical and Computer Engineering (CCECE), pages 406-411. ISSN 0840-7789. doi:10.1109/CCECE.2015.7129312.

Kanayama, Y., Kimura, Y., Miyazaki, F., and Noguchi, T., 1990. A stable tracking control method for an autonomous mobile robot. In Robotics and Automation, 1990. Proceedings., 1990 IEEE International Conference on, pages 384-389 vol.1. doi:10.1109/ROBOT.1990.126006.

Kanayama, Y., Kimura, Y., Miyazaki, F., and Noguchi, T., 1991. A stable tracking control method for a non-holonomic mobile robot. In Intelligent Robots and Systems '91. 'Intelligence for Mechanical Systems, Proceedings IROS '91. IEEE/RSJ International Workshop on, pages 1236-1241 vol.3. doi:10.1109/IROS. 1991.174669.

Kanjanawanishkul, K., 2005. Formation control of mobile robots: survey. eng. ubu. ac. th, pages 50-64.

Kowdiki, K. H., Barai, R. K., and Bhattacharya, S., 2012. Leader-follower formation control using artificial potential functions: A kinematic approach. In IEEE-International Conference On Advances In Engineering, Science And Management (ICAESM -2012), pages 500-505.

Liu, J. and Wang, X., 2011. Advanced Sliding Mode Control for Mechanical Systems. Springer-Verlag Berlin Heidelberg, 1 edition.

Martins, N. A., Elyoussef, E. S., Bertol, D. W., Pieri, E. R. D., Moreno, U. F., and d. B. Castelan, E., 2011. Trajectory Tracking of a Nonholonomic Mobile Robot with Kinematic Disturbances: A Variable Structure Control Design. IEEE Latin America Transactions, 9(3):276-283. ISSN 1548-0992. doi:10.1109/TLA.2011. 5893772.

Mastellone, S., Stipanovic', D. M., Graunke, C. R., Intlekofer, K. A., and Spong, M. W., 2008. Formation Control and Collision Avoidance for Multi-agent Non-holonomic Systems: Theory and Experiments. The International Journal of Robotics Research, 27(1):107-126. doi:10.1177/0278364907084441.

Raimúndez, C. and Paz, E., 2013. Adaptive mobile robots formation control using neural networks. In 2013 European Control Conference (ECC), pages 884-889.

Shaw, I. and Simões, M., 1999. Controle e modelagem fuzzy. Edgard Blucher. ISBN 9788521202486.

Utkin, V. and Shi, J., 1996. Integral sliding mode in systems operating under uncertainty conditions. In Decision and Control, 1996., Proceedings of the 35th IEEE Conference on, volume 4, pages 4591-4596 vol.4. ISSN 0191-2216. doi:10.1109/CDC.1996.577594.

Utkin, V. I., 1992. Sliding modes in control and optimization, volume 116. Springer-Verlag Berlin.

Wang, J., Rad, A., and Chan, P., 2001. Indirect adaptive fuzzy sliding mode control: Part I: fuzzy switching. Fuzzy Sets and Systems, 122(1):21 - 30. ISSN 0165-0114. doi:http://dx.doi.org/10.1016/S0165-0114(99)00179-7.

Yan-dong, L., Ling, Z., and Ming, S., 2013. Adaptive RBFNN Formation Control of Multi-mobile Robots with Actuator Dynamics. Indonesian Journal of Electrical Engineering and Computer Science, 11(4):1797-1806.

Maximilian Jaderson de Melo, Mauricio Begnini, Heber Rabelo da Silva, and Marcelo Christiano da França Júnior Robust and adaptive chatter free formation control of wheeled mobile robots with uncertainties
ADCAIJ: Advances in Distributed Computing and Artificial Intelligence Journal Regular Issue, Vol. 7 N. 2 (2018), 27-42 eISSN: 2255-2863 - http://adcaij.usal.es Ediciones Universidad de Salamanca - CC BY NC DC 
